Paideusis

\title{
Education and Recognition
}

\section{John White}

Volume 7, numéro 2, 1994

URI : https://id.erudit.org/iderudit/1073278ar

DOI : https://doi.org/10.7202/1073278ar

Aller au sommaire du numéro

Éditeur(s)

Canadian Philosophy of Education Society

ISSN

0838-4517 (imprimé)

1916-0348 (numérique)

Découvrir la revue

Citer cet article

White, J. (1994). Education and Recognition. Paideusis, 7(2), 3-12.

https://doi.org/10.7202/1073278ar d'utilisation que vous pouvez consulter en ligne.

https://apropos.erudit.org/fr/usagers/politique-dutilisation/ 


\section{Education and Recognition}

John White, Institute of Education University of London

\section{Introduction}

There has been much philosophical discussion in recent years about selfesteem and self-respect and the role of education in their cultivation. (On self-esteem, see, for instance, Dewhurst, 1991.) As far as I am aware, little has been said about the related topic of recognition. This paper is an attempt to map out some of the main issues in this area. Where self-esteem and self-respect have to do with how one sees oneself, recognition is concerned with how others see one. The two topics are linked, in that how one sees oneself in the former cases is often a function of how others see one. To that extent, 1 hope the discussion in this paper will also contribute to work on self-esteem and selfrespect. The ultimate destination will be the place of recognition in schooling. This will cover both the individual student's need for recognition and its role within the curriculum. But, first, I shall say something about the concept of recognition. Then, I shall look at the importance of recognition in human life in general, at whether it can be said to constitute a basic human need, and at its relation to the biologically more primitive notion of attention. After a brief discussion of fame as one form of recognition, I try in the final section to show how the foregoing discussion helps to throw light on matters to do with schooling.

\section{The concept of recognition}

In English, we talk of "recognition" in more than one context. Someone recognises an old school friend on a train. Someone else gets a pay rise, or a knighthood, in recognition of services rendered. There are clearly two concepts here. If the Queen recognises someone's work for the public weal by dubbing him a knight, she may well not recognise him in the first sense, since she may never have seen him before. Likewise, I may recognise someone on a train without according her any kind of public acknowledgment of having known her before (let alone of anything grander). While in another context it might be interesting to explore logical links between the two senses of the term, in this paper I shall be exclusively concerned with recognition as acknowledgment.

There is a gamut of cases here. I do not wish to imply by this that there is a single metric: the concept is too polymorphous for that. At the same time, there is more than an unchartable array: something of a progression from simpler to more complex cases. At one end of the range, we have something even more basic than acknowledging that one knows someone. This is acknowledging someone's presence. One need not know them. One recognises a person in this sense when one nods to someone on entering a room, or even when one lets someone get off the bus before one or adjusts one's path when walking along a street so as not to bump into someone. One might say that here one recognises a person as a person-a person in general, rather than as any particular person. The latter only comes into play when we move along the continuum to our earlier example, acknowledging that one knows an old friend. This kind of recognition can also take a more institutionalised form: there are 
obvious practical reasons why a student teacher calls on students by name to contribute to a lesson, but doing this can at the same time be a way of indicating that she knows who they are as individuals. Further along the line, we may place the practice of acknowledging what someone says. We have everyday ways of showing that we have registered what another has said, from "Really?"or "You did, did you?" to more complex responses. Very often, we want to go further, not simply to acknowledge having listened to them, but to indicate some kind of sharing of beliefs or values. We say "Right!" or "I couldn't agree more," and so on. This takes us into that part of the continuum where recognition goes beyond acknowledging people's existence, or what they say, to acknowledging what they are, are like, or have done. This includes recognition of social role or position-by curtsying to the Queen, for instance, or taking off one's hat when moumers pass one in a hearse. We also give people recognition for what they are like, for their personal qualities-by expressions of admiration, gratitude, or (sometimes) the desire to see someone again. As for achievements, we recognise these both in an informal way, by saying how much we like the room someone has decorated, for instance; or institutionally, by awarding certificates, prizes, bonuses, medals, and honours. ("Achievements" here may, but need not, include filling a social position or possessing desirable personal qualities.) The more widespread the recognition one acquires for one's social position, personal qualities, or achievements, the more famous one is.

\section{The importance to us of recognition}

We have, then, a range of cases from acknowledging someone's presence throngh to fame. Let us leave fame on one side for the moment. From the point of view of the recipient, most or all other kinds of recognition are usually held to be desirable: we tend to be upset when we fail to receive them. (It might be said that some forms of public recognition are worse than no recognition at all such as being designated the class dunce. But in my usage, this would not be a case of recognition, but of labelling. Recognition is for some kind of positive attribute-minimally, for being a person and worthy of respect as such, more expansively, for having certain desirable qualities or attainments.) At the more humdrum end of the range, people do not like it when others fail to register their presence. Individual students sometimes experience this in class when their teachers give them no indication that they know they are in the room. At a more general and dramatic-level, as William James, 1890, quoted in Glover, 1988) has said:

No more fiendish punishment could be devised, were such a thing physically possible, than that one should be turned loose in society and remain absolutely unnoticed by all the members thereof. If no one turned round when we entered, "cut us dead," and acted as if we were non-existing things, a kind of rage and impotent despair would ere long well up in us, from which the cruelest bodily tortures would be a relief; for these would make us feel that, however bad might be our plight, we had not sunk to such a depth as to be unworthy of attention at all.

Why is being ignored painful, either in everyday life or in more extreme ways, moving towards James' imaginary situation? In the worst cases-in some kinds of solitary confinement or slavery, perhaps-it is because there is no indication that we are being acknowledged as a member of human society at all. 
In more ordinary situations, our distress may arise from lack of acknowledgment that we belong to a particular social group, a school class, for instance.

As we move along the gamut, considerations of individuality, as well as sociality, become increasingly important. It might relieve the isolate's distress in a school class to be treated just like everybody else, even though the regime is authoritarian and leaves no child any opportunity to impose his or her own individual stamp. But when we move on to the example of someone whom a former friend fails to acknowledge, what is upsetting here is that the person is not being recognised as herself, as the particular individual Mary Smith, and not simply as a classmate in such and such a school (although this also may be a factor). One aspect of our individuality is having our own point of view, seeing things from our own perspective. Finding our remarks met by silence or treated as an interruption in another's monologue is unwelcome because it makes us feel that our point of view is unimportant. Our remarks, however, may receive this minimal level of recognition, but fail to elicit the social reinforcement embodied in approving comments like "That's right." The other person may appear either unmoved by what we are saying, or downright disapproving. What may upset us here is that the other person does not show that they accept the worthiness of what we say. This is important to us-as all cases of recognition are important to us-partly because we are social creatures. We want to be reminded that we belong, that we are accepted as members of the various social groups within which we live, and that we adhere to the values shared by those groups. This is not at all to say that we want other people always to agree with our particular judgments, but only that we want them to accord them a certain legitimacy and worth (assuming there is minimal room for this and we are not talking of utterly reprehensible opinions where it would be unreasonable to expect any kind of reinforcement). One facet of seeing the world from our own perspective is living out our life under the guidance of a personal hierarchy of values. By this, I do not mean that we create our values ourselves: as I have implied, I find no difficulty in the view that we take them over from our culture, and I merely have in mind that different individuals will to some extent give different weightings to these common values. What we wish for in our interlocutors is that, where they do not share our weightings in particular circumstances or in general, they do at least recognise that we may legitimately make them. This presupposes that we desire a sharing of values with them at a higher-order level-that is, that both parties take it as read that individuals are entitled to their own distinct ethical point of view. It should be clear that while recognition in this part of the continuum is closely connected with the ideal of individuality, or personal self-directedness, this does not mean that it has become detached from sociality. Recognition is necessarily a social phenomenon in all of its manifestations: A can only be recognised by B (or by B, C. . ), and this implies a social context from the start. The link between individuality and sociality comes about because in our kind of society, (as contrasted, say, with medieval society), individuality has come to be prized as a major social va' ue.

We now move on from what people say to what they are, are like, or achieve-perhaps we should say to what they may also otherwise achieve, seeing that one's contribution to a conversation or discussion may also count as an achievement. Here, too, we can be hurt by lack of recognition, whether people do not pay us due deference as a teacher or official, or misperceive our 
genuinely altruistic concern for someone else as a way of feathering our own nest, or whether our watercolour of dahlias fails are chosen for the local art exhibition, or the book on which we have slaved is not reviewed. Children, not least, can suffer in this way-if they get a low mark for a piece of work, for example, or if they feel that their parents or teachers fail to notice the efforts they have made to be more tidy or less naughty. Recognition of achievements in general, whether to do with personal qualities or with some kind of public product, is also characterised by both individuality and sociality. Failing to meet the mark with one's dahlias is not only to suffer frustration in the pursuit of a perscnal goal: it is also to be excluded from participating in a social event. As Alasdair MacIntyre (1981) has pointed out, co-operative activities for shared ends, which he calls "practices," play a large part in our conception of personal well-being. Within them, the distinction just made between personal qualities and public products tends to become blurred. A member of a hockey team is giverı recognition by her fellow players, as well, perhaps by spectators, not only for ber adeptness in scoring goals, but also because of her co-operativeness, good humour, and physical courage.

\section{Recognition as a basic need}

How far can the kinds of recognition we have been considering be classified as basic human needs? Much here will depend on the framework we have in mind. For bare survival, oxygen is certainly a basic need, but the different forms of recognition are probably not. If we are thinking, rather, of what is necessary for flourishing as a member of a community-any community, it would seem that people need to be publicly acknowledged to be members of it, and this brings with it approving recognition of the contributions they make to its well-being. In order to flourish as a member of a liberal community, one seems to need some kind of acknowledgment that one adheres to its specific values, has a personal point of view, and is part-author of one's life. If these suppositions are correct, it makes good sense to talk of recognition as a basic need relative to these different contexts.

The claim that recognition in its various forms is a basic human need does not imply that it must be actively sought. We may simply accord it to each other. Doing so is, indeed, normally taken for granted as a feature of social interaction. This, no doubt, has to do with its foundational importance in our life.

Despite its necessity to every human being-and sometimes because of its necessity, recognition is not always accorded, or the social conditions in which recognition flourishes do not always pertain. This can happen by design. A person can put someone down by deliberately ignoring what he or she says; a dictator can set up labour camps in which prisoners work as terrorised atoms. And it can happen by default. Through tiredness or anxiety, a teacher may ignore a child's contribution; and within a school, pedagogy may be conceived wholly as a transaction between a teacher and individual learners, thus eliminating the possibility of shared learning tasks and the opportunities for mutual recognition which these bring with them.

What happens when recognition is not forthcoming? We have already noted more than one reaction to the displeasure. Sometimes one takes it, rightly or wrongly, that the lack of recognition is justified, and one feels unworthy. 
One can also feel resentful, believing it to be unfair. Either way, one may withdraw into oneself, becoming depressed or bitter; or one may take some kind of active stand, complaining, or seeking the recognition one has not received. The latter is one source of the desire for recognition we find around us in society. (There are other sources than reaction to personal misfortune. In our kind of society, desiring and seeking certain kinds of recognition is itself a major cultural value. It is not always only for functional reasons that a university lecturer wants to become a professor, and his colleagues may well not think worse of him for that; higher civil servants may work with an eye to the honours list; top students in a class may have an eye to coming in the first three in the end-of-year exams.)

Another kind of reaction to lack of recognition consists neither in withdrawal nor in compensatory activity. Survivors of Nazi and Stalinist concentration camps have written of the importance of maintaining one's selfrespect, one's sense of human dignity in one's own person in the face of a deliberate and thoroughgoing failure to acknowledge one as a member of the community, or even as a human being (Levi, 1987). But a similar stance can be adopted to more ordinary ignorings and demeanings.

\section{Recognition and attention}

I wish to come back for a moment to those who seek recognition when deprived of it. We can all think of educational examples: children who never seem to do as well as their classmates and who badly want their teacher's approval, or teenagers who look for recognition outside the school's values as a member of a gang. But what are we to say of students who cause trouble in order to get attention? Are they always out for recognition, or is the attention they seek sometimes something distinct from this? In general, attention is the wider concept. Recognising someone is paying attention to him or her, but paying attention can go on in the absence of recognition. We can pay attention to a sunset. Seeking or enjoying attention can also occur without seeking or enjoying recognition. One of my cats fawns round me when it is time to feed him. He does not want to be recognised as a cat, or a member of the household, or an expert mouser: he simply wants attention. Should we think of this desire as a primordial, biologically given, form of the social, rather than a biological, desire for recognition and as something which human beings, not least buman children, may fall back on if their needs for recognition are not satisfied?

To try to answer these questions, it is helpful to turn to animal psychology. Ethologists' studies of social structures among non-human primates have picked out the importance of attention-giving and attention-receiving. Two kinds have been distinguished. Among baboons and macaques is found "agonistic" attention. This is hierarchically structured within a core of rankordered aggressive males. At their centre is the dominant male. It is important for the other males to know his whereabouts, so that together they can present a cohesive aggressive stance towards an attacker. They, therefore, keep a wary eye on the leader-partly, too, because he may direct aggression at them.

The second structure is called "hedonic" and is found-along with traces of agonistic attention-in chimpanzee society. This

has a fluid structure in which the individuals repeatedly disperse and come 
together again, frequently with excited sessions of mutual display acting to focus social cohesion. On these "carnival" occasions, mutual display is interspersed with appeasement and greeting gestures, and is then followed by much varied contact behaviour which eventually becomes focused on a single outstanding displayer. As the contact behaviour takes over and the excitement dies down, small groups of individuals or solitary animals go off to indulge various pursuits before the group as a whole reassembles on another occasion (Chance and Larsen, 1976, 482).

In their quieter state, chimpanzees often direct their attention towards physical objects and their manipulable potential (Chance and Larsen, 325-6). It is suggested that this greater flexibility of attention behaviour than in a dominancedeference society is connected with the more marked intelligence and inventiveness that one finds among chimpanzees.

It is tempting to suggest that the biological roots of recognition may lie in various forms of anthropoid attention-behaviour. What was once wholly instinctual may now have developed into conventional structures, dependent on human beings' possession of language, but still drawing on non-linguistic phenomena like display, bodily contact, and deference. Moreover, different kinds of recognition seem to parallel the two modes of sub-human social attention: on the one hand, deference-recognition in hierarchical societies, and on the other, more mutual kinds of acknowledgment among communities of equals. Compare the difference between the recognition accorded the master by the slave in Hegel's Phenomenology with the universal recognition he sees as belonging to Sittlichkeit (Hegel, 1807; Norman, 1981, 71-2).

How, on such a hypothesis, would recognition differ from social attention? The former would seem to be one species of the latter-and to have the same function as the latter in promoting the inner cohesiveness of a social group. Young children's social attention, and the forms of behaviour accompanying it, has to be directed in socially approved ways on to proper objects of recognition. Bestowing recognition, thus, becomes a voluntary act in the sense that individuals learn to do this under this concept. In this way, the possibility arises-though not in all societies-of a reflective stance towards the practice of giving and receiving recognition, and, therewith, of the replacement of forms thought to be undesirable with forms more in accordance with considered values.

A further suggestion might be that more primitive forms of social attention underlie recognition-behaviour, ready to move centre-stage when for some reasion recognition is absent. One reason might be that conceptual structures assi)ciated with recognition have not yet been acquired. There is some evidence that the attention-behaviour of pre-school children has affinities with that of chi npanzee society (see Chance and Larsen, 1976, 119-201). Another reason might be that individuals fail to receive recognition which is accorded to others. It is understandable, on the present view, if children whose school work fails to mest with approval resort to showing-off before their classmates (cf. display bebaviour among chimpanzees) or to forms of domination.

How far these hypotheses are sound I do not know. I put them forward as fru:tful-looking ideas which certainly need more analysis. If there is anything in them, however, they may help us to strengthen the case for recognition as a basic human need: if human societies are to exist, there may need to be human versions of anthropoid attention-behaviour to make them cohere together. 


\section{Fame}

In writing of types of recognition, I have so far excluded that end of the continuum to do with fame. It does not seem to be necessary to human flourishing that one's qualities or achievements are acknowledged by many people. That some should recognise them has already been granted, but in some cases those close to one-one's friends or immediate colleagues-may be enough. There are people who would not be satisfied with this. Part of their picture of their own well-being consists in being acknowledged, in some sense, by a large number of people-that is, as a top-dog within an institution, a rich person, a media star, or an artist of genius.

The focus at this point is not on seeking fame, only on welcoming it if it comes to one, sought or unsought. Does fame help one to flourish? It does not seem, as we have seen, to be a basic need, but this could still leave it as a good (being able to play the flute well is not a basic need, but it could still contribute to one's well-being). In favoured cases, it can be pleasant to feel that one is loved or appreciated by hundreds or millions: this can reinforce the thought that, through one's contribution, one has benefited many people. On the other hand, and notoriously, fame can lead one astray as much as it comforts. It is impossible to give a quick answer as to whether fame is personally desirable. The same is true about seeking fame. (For a lively discussion of the drive to "be somebody," see Palma, 1988). It is probably best to leave the issue at this point to novelists and dramatists to deal with in all the concreteness it requires.

Just one last point in this brief section. Not all desire for fame is desire for recognition. Sometimes, that is, where what is wanted is not only fame but power on a large scale, we may be dealing with the broader concept of attention. Stalin wanted the fearful attention of the whole Soviet population focused on himself. (He also wanted recognition; hence, his standard texts on histofy and the rebuilding of Moscow.)

\section{Recognition in school education}

I turn, finally, to applying some of these ideas to the place of recognition in the life of the school. As things frequently are, schools are in many ways reflections of society. Students are often encouraged to aim at high-status jobs and to equip themselves with the examination certificates which clear the way to these. It, thus, comes to be taken as read that recognition of status and achievement is a scarce commodity. Schools themselves can reinforce this message by systems of certificates, prizes, and other honours for the few. When schools encourage the most promising to aim for the heights, it is really not surprising that some should be attracted by the prospect of fame: if it is a virtue to go high, it must, it may seem, be a nobler virtue to go higher.

Schools can also reflect society in their attitudes to the less than promising, making them feel inadequate in relation to the elite, or rubbing in their unworthiness by giving them low-status curricula or courses in which they constantly do badly and putting them in low streams. What do these students do when they fail to get recognition for academic achievements? They may withdraw into themselves; they may seek recognition elsewhere, such as on the sports field, or in the peer group; they may fall back on attention-seeking-as 
clowns, bullies, or sexually attractive people; or they may seek vicarious recognition in the shoes of famous footballers or pop stars, daydreaming themselves into celebrities.

Another way in which schools mirror society is in the greater recognition which is often given to boys rather than girls. The predominance of men in high-status positions in society is matched in schools by boys getting the lion's share of teacher attention and encouragement. Whether this has biological roots in anthropoid societies, I do not know, but agonistic and hedonic forms of attention behaviour found in these and mentioned in an earlier section seem to be peculiarly male phenomena.

Schools need not copy the outside world. These days, the best are increasingly aware of the dangers of skewing their distribution of recognition. They see themselves as helping to reorder society, and not blindly to follow it. What, more precisely, might schools do?

First, and very generally, we can see them as sharing with parents the task of shaping biologically given forms of attention behaviour into approved forms of recognition behaviour. In a liberal democracy, the latter will be weighted towa:ds mutuality and universality and away from status and deference.

Second, and more specifically, staff could be individually and collectively very clear that certain forms of recognition are necessary for human flourishing, eithe $r$ in general or in a liberal democratic society, and should, therefore, be accorded not just to some students but to all. They could arrange their pedagogic practices and the ethos of the school so that everyone is accorded this recog,nition. This may come both from themselves and from other students. The Jatter can occur partly via shared learning activities embodying the features of MacIntyrean practices mentioned above. Teacher recognition is important both as a source of recognition in general- and, in this way, is on a par with other students'-and because of its specialised function in helping students to make progress in their learning. Students also need to be encouraged to give recognition to others. Sometimes this will require training them in various social skills- to do with conducting conversations, for instance-so that they know what to do when. Clearly, these competencies need to be taught not as isolated skills, which could be used to manipulate people, but should be cultivated along with benevolence of outlook and behaviour which makes it matter to students that all individuals receive the recognition they need to flourish.

This universal mutuality of recognition is one aspect of the wider value of equality of respect, on which relationships within the school should be based. The wider value also includes stand-off notions like non-interference and tolerance. In the present context, we are concerned not with refrainings, important as these are to cultivate in children, but with positive action on others' behalf. Recognition is premised on a care which the recogniser must have for the other's well-being. In this way, it is, perhaps, a form of love.

A school which attends to every member's need to give and to receive recognition is helping to strengthen in microcosm attitudes and dispositions necessary for democratic citizenship. It is putting before students another model of sccial life than one in which competition for status and prestige is so salient, ofter to the detriment of those who fail in it. Of course, many of those who pass through the school will be worsted in this competition. What the school can do for them is at least to build up in them-as part of its universal provision-a 
sense of self-respect strong enough to withstand lack of recognition. This must go along with some degree of intellectual grasp of what is happening to them in such situations. We will soon come to this.

Third, the assessment system of the school could be built around recording achievements rather than highlighting failure-as in the testing found in the National Curriculum introduced into England and Wales in 1988, for instance, where many students will probably suffer in their sense of self-worth through being judged to be behind the national average. Records of achievement can cover both scholastic matters and accomplishments of other kinds, to do with hobbies, interests, personal qualities, and activities in the community.

Fourth, as part of their self-understanding, students need to acquire some insight into the roles of recognition and of attention in human life. They have to be acquainted with the different forms it takes, with its universal importance, and with its key role in democratic citizenship. They can come to see that people sometimes seek more recognition than they need-and also that sone fall into the opposite error of thinking they can do without it through leading an unrealistically self- sufficient existence. Students can be brought to an understanding of many of the points mentioned in this paper-about the way, for instance in which lack of recognition can lead to a craving for attention; about the ill-distribution of recognition in society; about the fact that in a well-ordered community, recognition should not have to be sought, as it should occur unobtrusively as part of everyday social arrangements; and about rational attitudes to fame. In their own interests, they should also learn about pseudo-recognition-the according of recognition as a means to some end of the recogniser's and not for the other's sake including its prevalence in modern society in the shape of flattery, political propaganda, sales-talk, manipulation in the media.

Fifth, teachers and students could be aware of possible pitfalls in following a policy of universal mutual recognition. Although recognition is normally welcomed, it is not always. A child being praised before her classmates for outstanding work or good behaviour may know too well what this will lead to after class in the shape of the ribbing and taunting. Teachers may also be tempted, in their benevolence, to give excessive recognition to students for achievements which are scarcely achievements at all or, more generally, to exaggerate the quality of their achievements. This is not to deny that exaggeration may sometimes be appropriate; but if it happens as a matter of course, it may be harmful to a student both practically and in acquiring self-knowledge. Teachers need to acquire a delicacy of judgment in knowing when, where, how much, and in what ways to accord recognition. A second pitfall is in making recognition too salient in the school's life. Not all worthwhile achievements are public and, thus, candidates for recognition. Enjoying listening to classical music may be different in this regard from throwing pots for there need be no perceptible accomplishment. Students must certainly come to see that recognition is important in human life-but that not all achievements can elicit it. 
It is especially fitting in an essay on this theme to acknowledge the invaluable help that Patricia White has given me in clarifying my ideas and improving my written expression. I am also indebted to a penetrating Paideusis reader who helped me to improve this essay.

\section{References}

Chance, M. and R. Larsen (Eds.). The Social Structure of Attention. London: John Wiley, 1976.

Dewhurst, D.W. "Should teachers enhance their pupils' self-esteem?" Journal of Moral Education, 20(1), 1991, 3-11.

Glover, J. The Philosophy and Psychology of Personal Identity. London: Penguin Press, 1988. Chapter 16.

James, W. (1890). The Principles of Psychology. Reprinted by New York: Dover, 1950. Volume 1, 293.

Hegel, G. (1807). Phenomenology of Mind.

Levi, P. If This Is a Man. London: Abacus, 1987.

Macintyre, A. After Virtue. London: Duckworth, 1981. Chapter 14.

Norman, R. Hegel's Phenomenology. Sussex: Harvester Press, 1981.

Palma, A.B. "On Wanting to be Somebody." Philosophy, 63, 1988, 373-87. 